\title{
Detection of silent myocardial ischemia: Is it clinically relevant?
}

\author{
Mario Petretta, $M D,{ }^{a}$ Giovanni Fiumara, $M D,{ }^{b}$ Maria Piera Petretta, $M D,{ }^{c}$ and \\ Alberto Cuocolo, $\mathrm{MD}^{\mathrm{c}}$
}

\section{See related article, pp. 731-738}

Silent myocardial ischemia is defined as objective documentation of myocardial ischemia in the absence of angina or anginal equivalents. ${ }^{1}$ The first description of silent ischemia date to the 1970s, but despite intensive investigation, its pathophysiology, detection, prevalence, and clinical significance are still debated. The need and the benefit of treating silent ischemia, particularly in patients without history of coronary artery disease (CAD) and who are asymptomatic, remain questionable.

Asymptomatic (silent) myocardial ischemia may be identified during routine daily activities or during stress testing in patients without or with known CAD. ${ }^{1-3}$ One of the earliest investigations addressing the prevalence and significance of silent myocardial ischemia in asymptomatic subjects is the United States Air Force study, ${ }^{4}$ conducted in 1,390 men, 111 of whom had positive exercise tests. Thirty-four of these 111 (about $2.5 \%$ of the total) had coronary artery lesions of at least $50 \%$ stenosis. Thaulow et $\mathrm{al}^{5}$ studied 2014 Norwegian male office workers between 40 and 59 years of age (mean age 50 year). Coronary angiography in men with positive exercise tests demonstrated that 69 had stenoses of $50 \%$ or greater in one coronary artery; 50 of these (2.7\% of the total) patients were completely asymptomatic, a percentage similar to that found in the United States Air Force study. He et $\mathrm{al}^{6}$ reported in nearly 4,000 subjects studied, that the severity of coronary artery calcification by electron-beam computed tomography

From the Department of Translational Medical Sciences, ${ }^{\text {a }}$ University Federico II, Institute of Diagnostic and Nuclear Development, ${ }^{\mathrm{b}}$ SDN Foundation; and Department of Advanced Biomedical Sciences, ${ }^{c}$ University Federico II, Naples, Italy.

Reprint requests: Alberto Cuocolo, MD, Department of Advanced Biomedical Sciences, University Federico II, Via Pansini 5, 80131 Naples, Italy; cuocolo@unina.it.

J Nucl Cardiol 2013;20:707-10.

$1071-3581 / \$ 34.00$

Copyright $@ 2013$ American Society of Nuclear Cardiology.

doi:10.1007/s12350-013-9725-z
(CT) can predict silent myocardial ischemia on stress single-photon emission computed tomography (MPS). Silent myocardial ischemia was present in $2.6 \%$ of patients with coronary calcium score between 11 and $100,11.3 \%$ of patients with scores between 101 and 399, and $46 \%$ of patients with scores above 400 .

In this issue of the Journal, Malhotra et $\mathrm{al}^{7}$ evaluated the relationship between silent myocardial ischemia and CAD risk factors in a retrospective analysis of 1,354 asymptomatic patients without known CAD referred for stress MPS. The most common reasons for referral of these patients without chest pain or dyspnea were CAD risk factors, atrial fibrillation, and pre-operative evaluation. As expected, the prevalence of silent myocardial ischemia in these asymptomatic subjects was very low (7.2\%). The authors identified a positive relationship between the number of CAD risk factors and the prevalence of silent myocardial ischemia. However in older patients ( $>74$ years), who had a significantly greater prevalence of silent ischemia, the presence and number of risk factors were not predictive. The positive predictive value of an abnormal MPS for predicting angiographic CAD was only 53\% and, among all asymptomatic patients referred for stress MPS, significant anatomical CAD was found in only 31 of 1,354 (2\%) patients. Malhotra et $\mathrm{al}^{7}$ concluded that their findings support current guidelines, which generally advocate against routine testing in asymptomatic patients. Unfortunately, they did not provide outcome information for these patients, in particular for the 60 patients (4.4\% of overall study population) defined to have "prognostically significant ischemia" (i.e., $>10 \%$ of left ventricular myocardium).

Previous studies have found that silent myocardial ischemia detected in healthy individuals without known CAD has been shown to predict adverse events. The Lipid Research Clinic's Coronary Primary Prevention Trial (LRCPPT) ${ }^{8}$ and the Multiple Risk Factor Intervention Trial (MRFIT) ${ }^{9}$ showed that the presence of asymptomatic myocardial ischemia detected during baseline treadmill exercise testing in subjects without known CAD predicted a more than fivefold increased risk of coronary events and cardiac death during the 7- to 10-year follow-up period. Other studies evaluated 
the prevalence and significance of silent ischemia in asymptomatic subjects without known CAD by cardiac radionuclide imaging. Fleg ${ }^{10}$ evaluated 407 participants enrolled in the Baltimore Longitudinal Study of Aging, who had no clinical or resting electrocardiographic (ECG) evidence of CAD and underwent Tl-201 scintigraphy immediately following maximal treadmill exercise. Four subsets of subjects were derived: (1) negative ECG and negative Tl-201; (2) positive ECG and negative Tl-201; (3) negative ECG and positive Tl-201; (4) positive ECG and positive Tl-201. Over a mean follow-up of 4.6 years, cardiac events (angina pectoris, myocardial infarction, or cardiac death) occurred in 40 of 407 volunteers (9.8\%). Analysis revealed a $48 \%$ incidence of cardiac events in the 23 subjects (6\% of the study patients) with concordant abnormal ECG and Tl-201 test results vs an event rate of $3 \%-12 \%$ for the other subgroups $(P<.001)$. The authors also concluded that, if not practical for screening the general population, combined exercise ECG and myocardial scintigraphy warrants further investigation as a diagnostic strategy in high-risk subsets with additional coronary risk factors. The degree of silent ischemia may be more important than the simple presence of silent ischemia in the prediction of future events. Zellweger et $\mathrm{al}^{11}$ evaluated 3,664 consecutive asymptomatic patients without known CAD, who had undergone stress MPS. They determined that if a subject had $\geq 7.5 \%$ ischemic myocardium, then their risk of a cardiovascular event was significantly increased. Age, male sex, diabetes, and hypertension were the most powerful pre-test variables that predicted prognostically high-risk ischemia.

Special consideration requires the role of diabetes in predicting the presence of silent myocardial ischemia. In the study of Malhotra et al, ${ }^{7}$ of the 1,354 patients evaluated, only $22 \%$ had diabetes; nevertheless, by multivariable analysis, diabetes was a strong predictor of silent myocardial ischemia $(P<.001)$ with an odds ratio of 2.24, while the independent predictive value of the other risk factors was lower or even absent. As a result of the study by Haffner et al, ${ }^{12}$ diabetes is presently considered a CAD risk equivalent according to the Education Program guidelines. ${ }^{13}$ This means that patients with diabetes have a risk for coronary events similar to that of patients without diabetes who have already had an event. However, whether diabetes is per se CAD equivalent is controversial. A meta-analysis involving in excess of 45,000 patients did not support the hypothesis that diabetes is a "coronary heart disease equivalent," and suggests that public health decisions to initiate cardio-protective drugs in patients with diabetes for primary coronary heart disease prevention should therefore be based on appropriate patients' risk estimates rather than a "blanket" approach of treatment. ${ }^{14}$ Recently, Painter et $\mathrm{al}^{15}$ found that in both women and men with baseline diabetes there was a significant improvement in predictive ability of cardiovascular risk using models incorporating hemoglobin $A_{1 c}$ levels compared to classification of diabetes as a cardiovascular risk equivalent. Hence, it is not the diabetic status but the additional CAD risk factors that confer the CAD equivalent state in diabetic patients. Certain clinical and biological variables are what appear to confer the $\mathrm{CAD}$ equivalent state in diabetic subjects.

As Malhotra et $\mathrm{al}^{7}$ state, the prevalence and significance of silent myocardial ischemia in asymptomatic diabetics is a hotly debated topic. Rajagopalan et $\mathrm{al}^{16}$ found in 59\% of 1,741 asymptomatic diabetic patients had an abnormal MPS. Male sex, age, resting ECG abnormalities, hypertension, insulin use, and pharmacologic stress were predictors of a high-risk scan. On the other hand, the Detection of Ischaemia in Asymptomatic Diabetics (DIAD) study ${ }^{17}$ found a lower prevalence (22\%) of silent myocardial ischemia in 1,123 diabetic patients. In particular, moderate or large perfusion defects were present in 33 patients and the strongest predictors for abnormal tests were an abnormal response to Valsalva, male sex, and diabetes duration. In this study, other traditional cardiac risk factors or inflammatory and prothrombotic markers were not predictive. Ischemic adenosine-induced ST-segment depression with normal perfusion $(\mathrm{n}=21)$ was associated with the female gender (odds ratio 3.4). Selecting only patients who met contemporary American Diabetes Association guidelines, ${ }^{18}$ (i.e. those with 2 or more risk factors for CAD) would have failed to identify $41 \%$ of patients with silent ischemia. A post hoc analysis of the DIAD study was performed to assess cardiac event rates and the effect of screening on outcomes according to the patients' baseline cardiovascular risk. ${ }^{19}$ The authors concluded that a substantial portion of the DIAD population was defined as having intermediate to high baseline cardiovascular risk. Nevertheless, the annual cardiac event rate was low $(<1 \%)$ in all risk groups, and not altered by routine screening for inducible ischemia. More recently, Acampa et $\mathrm{al}^{20}$ assessed the comparative ability of stress MPS risk markers using varied iterative and risk classification approaches in asymptomatic diabetic patients. They also evaluated the temporal characteristics of cardiac risk according to MPS findings. A total of 436 consecutive asymptomatic diabetic patients who underwent stress-rest gated MPS were prospectively enrolled as part of the Impact of Inducible Ischemia by Stress SPECT (IDIS) trial. $^{21,22}$ Multivariable Cox proportional hazards model was employed to estimate cardiac death and nonfatal myocardial infarction. Risk reclassification was calculated and parametric survival analysis was used to predict 
time to events. At multivariable analysis, post-stress left ventricular ejection fraction and stress MPS ischemia were independent predictors of CAD death or myocardial infarction (both $P<.01$ ). The net reclassification improvement by adding MPS results to a model including pre-test CAD likelihood was 0.25 (95\% confidence interval 0.06-0.44, $P<.01)$. Parametric survival analysis showed that the highest probability of CAD death or myocardial infarction, and the major risk acceleration over time, occurred in patients with stress MPS ischemia and a post-stress left ventricular ejection fraction $\leq 45 \%$. Thus, in asymptomatic diabetic patients, using MPS, analytical approaches that establish the reclassification of risk for events may serve for better estimate outcomes at long-term follow-up. A recent American Diabetes Association position paper states that in asymptomatic patients, routine screening for CAD is not recommended, as it does not improve outcomes as long as cardiovascular risk factors are treated (level of evidence A). ${ }^{23}$ To identify the presence of CAD in diabetic patients without clear or suggestive symptoms, a risk factor-based approach to the initial diagnostic evaluation and subsequent follow-up has intuitive appeal. However, recent studies concluded that using this approach fails to identify which patients with type 2 diabetes will have silent ischemia on screening tests. ${ }^{17,24}$ Finally, routine screening does not appear to affect overall outcome of asymptomatic patients with type 2 diabetes. ${ }^{25}$

Malhotra et $\mathrm{al}^{7}$ showed that among asymptomatic patients without known CAD, the prevalence of silent myocardial ischemia on stress MPS is low and is related to the number of traditional CAD risk factors only among patients younger than 74 years of age. Although they concluded that routine stress testing in an asymptomatic population with a low prevalence of CAD carries a low diagnostic yield, evidence accumulated in recent years demonstrated that asymptomatic myocardial infarction or asymptomatic myocardial ischemia occurs frequently in diabetic patients. Thus, further studies should be performed to prospectively evaluate the frequency and duration of silent ischemic events in a larger number of well-characterized patients. It will also be of great interest for clinicians to determine whether the treatment of silent ischemia is useful for preventing cardiac events in patients without known CAD. For this purpose, careful selection not only of the study population but also of the techniques for detection of silent myocardial ischemia are necessary to accomplish its maximal clinical utility.

\section{Conflict of interest}

The authors have indicated that they have no financial conflict of interest.

\section{References}

1. Cohn PF, Fox KM, Daly C. Silent myocardial ischemia. Circulation 2003;108:1263-77.

2. Petretta M, Bonaduce D, Bianchi V, Vitagliano G, Conforti G, Rotondi $\mathrm{F}$, et al. Characterization and prognostic significance of silent myocardial ischemia on predischarge electrocardiographic monitoring in unselected patients with myocardial infarction. Am J Cardiol 1992;69:579-83.

3. Bonaduce D, Petretta M, Lanzillo T, Vitagliano G, Bianchi V, Conforti G, et al. Prevalence and prognostic significance of silent myocardial ischaemia detected by exercise test and continuous ECG monitoring after acute myocardial infarction. Eur Heart $\mathbf{J}$ 1991;12:186-93.

4. Froelicher VF, Thompson AJ, Longo MR Jr, Triebwasser JH, Lancaster MC. Value of exercise testing for screening asymptomatic men for latent coronary artery disease. Prog Cardiovasc Dis 1976;18:265-76.

5. Thaulow E, Erikssen J, Sandvik L, Erikssen G, Jorgensen L, Cohn PF. Initial clinical presentation of cardiac disease in asymptomatic men with silent myocardial ischemia and angiographically documented coronary artery disease (the Oslo Ischemia Study). Am J Cardiol 1993;72:629-33.

6. He ZX, Hedrick TD, Pratt CM, Verani MS, Aquino V, Roberts R, et al. Severity of coronary artery calcification by electron beam computed tomography predicts silent myocardial ischemia. Circulation 2000;101:244-51.

7. Malhotra S, Sharma R, Kliner DE, Follansbee WP, Soman P. Relationship between silent myocardial ischemia and coronary artery disease risk factors. J Nucl Cardiol 2013 (in press).

8. Ekelund LG, Suchindran CM, McMahon RP, Heiss G, Leon AS, Romhilt DW, et al. Coronary heart disease morbidity and mortality in hypercholesterolemic men predicted from an exercise test: The lipid research clinics coronary primary prevention trial. J Am Coll Cardiol 1989;14:556-63.

9. Mortality rates after 10.5 years for participants in the Multiple Risk Factor Intervention Trial. Findings related to a priori hypotheses of the trial. The Multiple Risk Factor Intervention Trial Research Group. JAMA 1990;263:1795-801.

10. Fleg JL. Prevalence and prognostic significance of exerciseinduced silent myocardial ischemia in apparently healthy subjects. Am J Cardiol 1992;69:14B-8B.

11. Zellweger MJ, Hachamovitch R, Kang X, Hayes SW, Friedman JD, Germano G, et al. Threshold, incidence, and predictors of prognostically high-risk silent ischemia in asymptomatic patients without prior diagnosis of coronary artery disease. J Nucl Cardiol 2009;16:193-200.

12. Haffner SM, Lehto S, Rönnemaa T, Pyörälä K, Laakso M. Mortality from coronary heart disease in subjects with type 2 diabetes and in nondiabetic subjects with and without prior myocardial infarction. N Engl J Med 1998;339:229-34.

13. Grundy SM, Cleeman JI, Merz CN, Brewer HB Jr, Clark LT, Hunninghake DB, et al. Implications of recent clinical trials for the National Cholesterol Education Program Adult Treatment Panel III guidelines. Circulation 2004;110:227-39.

14. Bulugahapitiya U, Siyambalapitiya S, Sithole J, Idris I. Is diabetes a coronary risk equivalent? Systematic review and meta-analysis. Diabet Med 2009;26:142-8.

15. Painter NA, Morello CM, Singh RF, McBane SE. An evidencebased and practical approach to using bydureon ${ }^{\mathrm{TM}}$ in patients with type 2 diabetes. J Am Board Fam Med 2013;26:203-10.

16. Rajagopalan N, Miller TD, Hodge DO, Frye RL, Gibbons RJ. Identifying high-risk asymptomatic diabetic patients who are 
candidates for screening stress single-photon emission computed tomography imaging. J Am Coll Cardiol 2005;45:43-9.

17. Wackers FJ, Young LH, Inzucchi SE, Chyun DA, Davey JA, Barrett EJ, et al. Detection of silent myocardial ischemia in asymptomatic diabetic subjects: The DIAD study. Diabetes Care 2004;27:1954-61.

18. Consensus development conference on the diagnosis of coronary heart disease in people with diabetes: 10-11 February 1998, Miami, Florida. American Diabetes Association. Diabetes Care 1998;21:1551-9.

19. Bansal S, Wackers FJ, Inzucchi SE, Chyun DA, Davey JA, Staib $\mathrm{LH}$, et al. Five-year outcomes in high-risk participants in the detection of ischemia in asymptomatic diabetics (DIAD) study: A post hoc analysis. Diabetes Care 2011;34:204-9.

20. Acampa W, Petretta M, Daniele S, Del Prete G, Assante R, Zampella $\mathrm{E}$, et al. Incremental prognostic value of stress myocardial perfusion imaging in asymptomatic diabetic patients. Atherosclerosis 2013;227:307-12.
21. Petretta M, Acampa W, Evangelista L, Daniele S, Ferro A, Cuocolo A. Impact of inducible ischemia by stress SPECT in cardiac risk assessment in diabetic patients: Rationale and design of a prospective, multicenter trial. J Nucl Cardiol 2008;15:100-4.

22. Acampa W, Petretta M, Evangelista L, Daniele S, Xhoxhi E, De Rimini ML, et al. Myocardial perfusion imaging and risk classification for coronary heart disease in diabetic patients. The IDIS study: A prospective, multicentre trial. Eur J Nucl Med Mol Imaging 2012;39:387-95.

23. American Diabetes Association. Standards of medical care in diabetes-2013. Diabetes Care 2013;36:S11-66

24. Scognamiglio R, Negut C, Ramondo A, Tiengo A, Avogaro A. Detection of coronary artery disease in asymptomatic patients with type 2 diabetes mellitus. J Am Coll Cardiol 2006;47:65-71.

25. Young LH, Wackers FJ, Chyun DA, Davey JA, Barrett EJ, Taillefer R, et al. Cardiac outcomes after screening for asymptomatic coronary artery disease in patients with type 2 diabetes: The DIAD study: A randomized controlled trial. JAMA 2009;301:1547-55. 